\title{
Factors shaping distribution and abundance of raptors wintering in two large Mediterranean islands
}

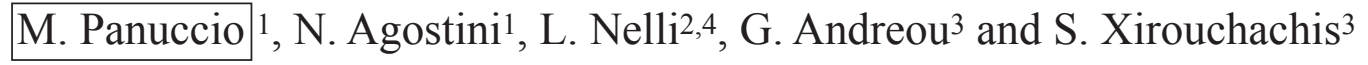 \\ ${ }^{1}$ MEDRAPTORS (Mediterranean Raptor Migration Network), Via Mario Fioretti 18, 00152 Rome, Italy \\ Institute of Biodiversity Animal Health and Comparative Medicine, University of Glasgow, G12 8QQ, Glasgow, UK \\ ${ }^{3}$ Natural History Museum of Crete, University of Crete, P.O. Box 2208, Heraklion 71409, Crete, Greece \\ ${ }^{4}$ Corresponding author. luca.nelli@glasgow.ac.uk
}

Keywords: Ecological barriers, Inter-specific competition, More Individuals Hypothesis, Movement ability.

\begin{abstract}
A growing number of ecological studies suggest that animal distributions are not only influenced by classical ecological features such as habitat availability, but also by the motion capacity of the studied animal. Here we analyse the diversity and density of two wintering raptor communities from Crete and Sicily, two large Mediterranean islands located along migratory flyways. We performed 611 and $1030 \mathrm{~km}$ of transects in Crete and Sicily respectively, examining the spatial distribution of raptors in relation to land use, topography, raptor species diversity and abundance. Our results show that community diversity and specific abundance are strictly related in accordance with the 'More Individuals Hypothesis'. Comparing the two most common raptors, the density of the Eurasian kestrel was the highest in Sicily and that of the common buzzard in Crete. An overall positive effect of Eurasian kestrel density on that of the common buzzard was found in both islands, but higher in Crete. Our findings suggest that the distribution and density of the Eurasian kestrel, because of its higher movement ability, are less influenced by the presence of ecological barriers along potentially migratory flyways. We cannot exclude that higher inter specific competition with common buzzards in Crete might have pushed the smaller species to cross the Mediterranean Sea in order to overwinter in Africa.
\end{abstract}

Nomenclature: BirdLife International (2004)

Abbreviations: KIA-Kilometric Index of Abundance, KmH-Kilometric raptor diversity index, VIF-Variance Inflation Factor.

\section{Introduction}

Species distribution ranges over the Earth's surface are linked to variables such as inter and intra-specific interactions and habitat availability and heterogeneity (Elith and Leathwick 2009). Coexistence requires species to be different in the way they affect, and are affected by, resources. In other words, coexistence requires some form of niche difference or partitioning where species' niche consists of four major axes: resources, natural enemies, space and time (Chesson 2000). It has been recently pointed out that, in order to understand mechanisms of species distribution patterns, it is essential to account not only for classical ecological features but also for the movement and dispersal ability of an organism, defined as a change in spatial location in time (Nathan et al. 2008, Cumming et al. 2012, Panuccio et al. 2015). All of these processes interact in shaping the structure and dynamics of populations, communities and ecosystems. The extent an animal moves during its life cycle is a balanced compromise between successful reproduction, foraging, predation avoidance and movement energy expenditure. Any variables adding additional costs should be weighted to explain the species' distribution, i.e. density of conspecifics or of other species with overlapping ecological niche, as well as any environmental feature that increases the cost of movement, such as ecologi- cal barriers (Beyer et al. 2016). Animals can cross or circumnavigate barriers, but this can be risky or time consuming. At the end of the breeding season, a huge number of Palearctic birds move into wintering areas. During such migratory movements they face barriers such as the Mediterranean Sea and the Sahara Desert. Some species spend the winter along the northern coast of the Mediterranean basin, while others reach Africa by making non-stop flights over sea or performing long detours in order to reach the Strait of Gibraltar (Spain) and the Bosporus (Turkey; Mellone et al. 2011, Panuccio et al. 2012). Among birds, raptors show a high level of mobility outside of the breeding period, and are expected to be distributed along similar latitudinal gradients, at varying densities depending on habitat availability (Newton 1979). However, it is now assumed that environmental, movement-related and historical factors should be tested in order to investigate the current biogeographical pattern of a given species (Guisan 2006, Cumming et al. 2012).

In this study, we analyze two raptor communities wintering in two large Mediterranean islands, facing substantial water bodies and located along different migratory flyways. We compare habitat structure, community diversities and relative species abundance in relation to ecological features (land use, topography), focusing in particular on the two most common species, the Eurasian kestrel (Falco tinnunculus, hereafter 
kestrel) and the common buzzard (Buteo buteo, hereafter buzzard). These species show a marked difference in their mobility. In particular, the buzzard is reluctant to cross large bodies of water during migration, while the kestrel is less constrained by the distribution of land masses and can safely fly over large stretches of sea (Malmiga et al. 2014, Agostini et al. 2015a)

\section{Material and methods}

\section{Study areas}

We selected two large Mediterranean islands, Crete and Sicily (Fig. 1). Both are located along raptor migratory flyways at approximately the same latitude (Panuccio 2011, Lucia et al. 2011, Agostini et al. 2015b). To reach Crete, raptors face a sea-crossing of at least $100 \mathrm{~km}$, taking the most direct route between the continental landmass and Crete. However, raptors can reach Crete moving by island hopping, through the island of Antikythira, with the longest non-stop flight over sea of about $35 \mathrm{~km}$. On the other hand Sicily is much closer to the continent (less than $3 \mathrm{~km}$ ). Crete is located in Southern Greece, between the Balkan Peninsula and Libya in North Africa, approximately $270 \mathrm{~km}$ to the nearest continental landmass. It covers an area of $8,336 \mathrm{~km}^{2}$, with a human density of 74.74 per $\mathrm{km}^{2}$. The highest mountains rise to 2,456 meters a.s.1.. During autumn migration substantial numbers of migrating raptors approach Crete from the Peloponnese Peninsula, passing across the small island of Antikhytira (Lucia et al. 2011). A large part of this migratory flow moves toward Africa, but hundreds of raptors, including common buzzards, stop in Crete for the winter (Panuccio et al. 2013). Sicily is located south of the Italian Peninsula, and is the largest island in the Mediterranean Basin, with an area of 25,832 $\mathrm{km}^{2}$. The shortest distance between Sicily and North Africa is about $150 \mathrm{~km}$, at the Channel of Sicily between Tunisia and Western Sicily. Human density is about 195.6 per $\mathrm{km}^{2}$. The highest elevation is Mount Etna, a volcano peaking at 3,343 meters a.s.1.. Sicily is crossed by a significant migratory flow of raptors twice a year. In this case, most birds pass over towards Africa during autumn, with mostly long distance migrant raptor species observed at the Strait of Messina (Zalles and Bildstein 2000, Panuccio 2011).

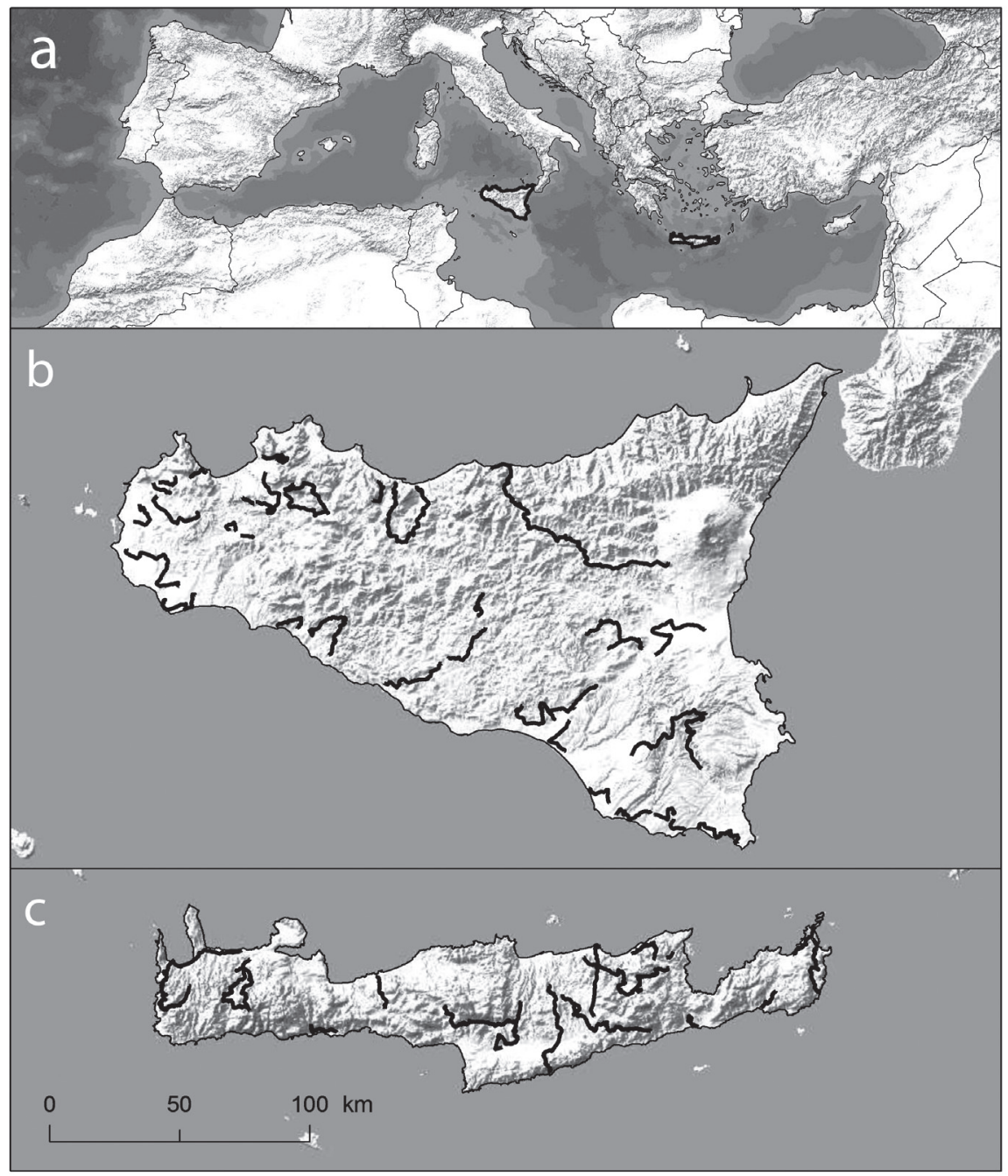

Figure 1. Location of the two islands in the Mediterranean Sea (a) and distribution of line transects in Sicily (b) and in Crete (c). 


\section{Data collection}

Fieldwork. We performed car transects on both islands, 20 in Crete (January 2009), for an average length of $30.6 \mathrm{~km}$ and an overall effort of $611 \mathrm{~km}$, and 39 in Sicily (January 2010), for an average length of $26.4 \mathrm{~km}$ each, that totaled $1030 \mathrm{~km}$. We conducted road counts driving at low-speed $(20-40 \mathrm{~km} / \mathrm{h})$, employing at least two observers and avoiding unfavorable weather conditions (rain, fog, strong wind). Counts were initiated two hours after sunrise and ended one hour before sunset (Bibby et al. 2000). Moreover, since a previous study suggested that raptors are attracted by fringes along main roads (Meunier et al. 2000), all transects were carried out on secondary roads. Whenever a raptor was sighted, the car was stopped long enough to allow species identification and data collection. The relevant data recorded were: species, date/ time, perpendicular distance from the transect $(\mathrm{m})$, side of the road and coordinates of observation along transects (GPS point). We used a Leica optical range finder (Rangemaster CRF 1600B, $7 \times 24$, error $\pm 1 \mathrm{~m}$ ) that included a clinometer to measure the radial distance between the raptor and the observers, and its angle on the horizon. A compass was used to measure the angle between the transect axis and the observation point. We then used these three measurements to obtain the perpendicular distance between observers and flying raptors, considering therefore the ground projection of the observed bird perpendicular to the road. Coordinates were recorded using a Garmin Colorado 300 GPS.

Habitat variables. QuantumGIS software (QGIS Development Team, 2014) was used to measure the percentage of habitat variables in a $1600 \mathrm{~m}$ wide strip along each transect, $800 \mathrm{~m}$ being the maximum distance recorded during the raptor counts. In particular, we used Corine Land Cover variables (Büttner and Kosztra 2007), grouping them into six categories: artificial surfaces (human infrastructure e.g. houses and buildings), permanent crops (olive groves, vineyards), pasture/arable land, complex cultivation patterns (heterogeneous agricultural areas with juxtaposition of small parcels of diverse annual crops, pasture and/or permanent crops), forest and scrubland. Furthermore, the LecoS tool for QGIS (Jung, 2013) was used to calculate: mean patch size expressed in square meters; mean shape index, a measure of patch complexity, where 1 indicates all patches are circular with values increasing as the patches become more irregular; and the Shannon diversity index, to account for the diversity of cover types. Using a $75 \mathrm{~m}$ digital elevation model, we derived 5 orographic variables for each transect length: average altitude, slope, northness, ruggedness and amount of solar radiation during January. Northness was calculated as the cosine of aspect (Zar 1999). Ruggedness was expressed as the variation in three-dimensional orientation of adjacent cells (Riley et al. 1999). Solar radiation was expressed in $\mathrm{Wh} / \mathrm{m}^{2}$ and was defined as a product of daily and seasonal shift of sun angle, along with variation in elevation, orientation (slope and aspect), and shadows cast by topographic features.

\section{Data analysis}

Raptor community. For each transect we calculated a kilometric index of abundance (KIA) of each species, dividing the number of raptor records by the distance $(\mathrm{km})$ covered and a kilometric raptor diversity index ( $\left.\mathrm{KmH}^{\prime}\right)$ by the formula

$$
K m H^{\prime}=-\frac{1}{L} \sum_{i=1}^{R} p_{i} \ln p_{i}
$$

where $L$ is the transect length and $p_{i}$ is the proportion of raptors of the $i$-th species, obtained by dividing the number of the species sightings by the total number of raptor observations in the transect. Higher values of $\mathrm{KmH}^{\prime}$ 'indicate a higher raptor diversity. For preliminarily comparison of the two islands, we tested for differences in habitat, species composition and relative species abundance between the two sets of samples of transects. We compared the habitat variables and landscape metrics measured in the strips around transects (KIA and $\mathrm{KmH}$ ') by applying Mann-Whitney $U$ tests.

Buzzard and kestrel density. Since records of buzzards and kestrels were prevalent (see Results), we estimated the densities of these species by line transect distance sampling (Buckland 2001, Thomas et al. 2010). We first used the conventional distance sampling engine in the Distance software (CDS), pooling the observed distances to obtain a global estimate of the detection function and expected cluster size, and stratified the encounter rate by the two study areas and by species to obtain density estimates of each species in each island. We then used the multiple covariate engine (MCDS) (Marques et al. 2007), taking the species and study area as factor covariates. In both cases we performed our estimation starting from half-normal, hazard-rate and uniform key functions with Hermite and simple polynomial series adjustment, and then chose the best model according to the Akaike's Information Criterion (AIC) and $\chi^{2}$ goodness-of-fit statistics $\left(\mathrm{GOF} \chi^{2}\right)$. To estimate expected cluster size we used both sizebiased regression method and, if the regression was not significant, we averaged the size of detected clusters. Sampling variance was estimated empirically. The best model obtained was used to calculate kestrel and buzzard density for each island, and subsequently for each transect.

Habitat effect on raptors. To evaluate the effect of habitat parameters on the density of the two species and on the raptor community, we performed three linear models. For habitat variable selection we followed a 'two stages' stepwise approach. First, we examined for multicollinearity among predictors, based on the calculation of variance inflation factor (VIF) (Zuur et al. 2010). We obtained the VIF for each j-th explanatory variable by starting from the full dataset by using the formula:

$$
V I F_{j}=\frac{1}{1-R_{j}^{2}}
$$

where $R_{j}^{2}$ is the $R^{2}$ of a linear regression of the $j$-th variable on the other covariates. We followed a stepwise procedure, calculating the VIF of each explanatory variable. At each step, we eliminated the variable with the highest VIF from the global model and we stopped when all the variables in the 
Table 1. Total counts, average values $( \pm \mathrm{SE})$ of KIAs and $\mathrm{KmH}^{\prime}$ in the transects of the two study areas and significance of MannWhitney U test.

\begin{tabular}{|c|c|c|c|c|c|}
\hline \multirow[t]{2}{*}{ Species } & \multicolumn{2}{|c|}{ Observed individuals } & \multicolumn{2}{|c|}{ KIAs } & \multirow[b]{2}{*}{ P-value } \\
\hline & Sicily & Crete & Sicily & Crete & \\
\hline Common buzzard & 147 & 307 & $0.19(0.027)$ & $0.54(0.073)$ & $<0.001$ \\
\hline Eurasian kestrel & 278 & 57 & $0.31(0.037)$ & $0.10(0.016)$ & $<0.001$ \\
\hline Peregrine falcon & 6 & 2 & $0.00(0.002)$ & $0.00(0.001)$ & 0.484 \\
\hline Eurasian sparrowhawk & 3 & 6 & $0.01(0.005)$ & $0.01(0.004)$ & 0.376 \\
\hline Booted eagle & 11 & 4 & $0.01(0.006)$ & $0.01(0.005)$ & 0.962 \\
\hline Marsh harrier & 10 & 0 & $0.00(0.001)$ & $0.00(0.000)$ & 0.067 \\
\hline Lanner falcon & 1 & 0 & $0.00(0.002)$ & $0.00(0.000)$ & 0.474 \\
\hline Hen harrier & 2 & 0 & $0.00(0.001)$ & $0.00(0.000)$ & 0.307 \\
\hline Black kite & 1 & 7 & $0.00(0.001)$ & $0.01(0.006)$ & 0.207 \\
\hline Lesser kestrel & 3 & 1 & $0.00(0.000)$ & $0.00(0.001)$ & 0.983 \\
\hline Griffon vulture & 0 & 108 & $0.00(0.000)$ & $0.13(0.047)$ & $<0.001$ \\
\hline Bearded vulture & 0 & 6 & $0.00(0.000)$ & $0.01(0.003)$ & $<0.001$ \\
\hline Golden eagle & 0 & 5 & $0.00(0.000)$ & $0.00(0.003)$ & 0.014 \\
\hline Bonelli's eagle & 0 & 1 & $0.00(0.000)$ & $0.00(0.001)$ & 0.163 \\
\hline Northern goshawk & 0 & 1 & $0.00(0.000)$ & $0.00(0.001)$ & 0.163 \\
\hline Greater spotted eagle & 0 & 1 & $0.00(0.000)$ & $0.00(0.004)$ & 0.163 \\
\hline $\mathrm{KmH}^{\prime}$ & 147 & 307 & $0.06(0.009)$ & $0.05(0.010)$ & 0.426 \\
\hline
\end{tabular}

subset had a VIF $\leq 5$ (Rogerson 2001). Using the qualifying variables obtained, we selected the best subset in a stepwise approach based on the calculation of Akaike's Information Criterion value, corrected for small sample size (Burnham and Anderson 2002). Our final results were validated by checking the normal distribution of residuals with a ShapiroWilk normality test and visual inspection of QQ-plot. Model fit was evaluated by visual inspection of residuals versus fitted values plot to verify homogeneity (Zuur et al. 2009).

\section{Results}

\section{Raptor community}

In the two study areas we collected 454 observations of buzzard, 335 of kestrel, 8 of peregrine falcon (Falco peregrinus), 9 of Eurasian sparrowhawk (Acciputer nisus), 15 of booted eagle (Hieraaetus pennatus), 10 of marsh harrier (Circus aeruginosus), 1 of lanner falcon (Falco biarmicus), 2 of hen harrier (Circus cyaneus), 8 of black kite (Milvus migrans), 4 of lesser kestrel (Falco naumanni), 108 of griffon vulture (Gyps fulvus), 6 of bearded vulture (Gypaetus barbatus), 5 of golden eagle (Aquila chrysaetos), 1 of Bonelli's eagle (Aquila fasciata), 1 of Northern goshawk (Accipiter gentilis) and 1 of greater spotted eagle (Clanga clanga). Overall, we detected significant differences in the relative abundance (KIA) and densities (distance sampling) of buzzards and kestrels, between the two islands. In particular, we found a higher abundance of kestrels in Sicily, whereas the other species were observed more frequently on Crete (Table 1). From comparison between habitat variables in the two areas we found a significantly higher proportion of pasture and arable land in Sicily. In Crete there was a greater percentage of complex cultivation patterns and scrubland, but no differences in habitat diversity (Shannon index) emerged between sites. On average, patches were larger (MPS) and more complex in Crete, with a higher mean shape index (MSI), while the orography was characterized by a higher ruggedness and a lower slope (Table 2).

\section{Common buzzard and Eurasian kestrel density}

Among all possible Distance models, the best one was a hazard rate key function, with no series-term correction and with species as covariate (Table 3 ). No differences in detectability were found between the two islands, but the separated curves for the two species showed that the detectability of kestrels decreased more rapidly than that of buzzards. For instance, at 200 meters from the observer the kestrel had a detection probability of 0.2 and the buzzard 0.5 (Fig. 2). Density estimations show marked differences between the two study areas and the two species as well. Density estimations were of 0.75 kestrels per $\mathrm{km}^{2}$ and 0.36 buzzards per $\mathrm{km}^{2}$ in Sicily, with a percent coefficient of variation (CV) of $12.82 \%$ and $16.52 \%$ respectively. In Crete we estimated a density of 0.26 kestrels $(\mathrm{CV}=14.86)$ and 0.91 buzzard per $\mathrm{km}^{2}(\mathrm{CV}$ $=9.32 \%$ ).

\section{Effect of habitat on raptors}

The three linear models of the candidate predictor variables on the buzzard density, the kestrel density and raptor diversity, were characterized by normal residual distributions (Shapiro tests, respectively $W=0.974$ and $P=0.235$; $W=0.963$ and $P=0.070 ; W=0.972$ and $P=0.201$ ). In the buzzard model (Table 4), an overall positive effect of kestrel density was found, although the negative interaction with the island indicates that the positive effect is significantly higher in Crete (Fig. 3a). The KmH index was positively associated with buzzard density but no differences emerged between the 
Table 2. Average values $( \pm \mathrm{SE})$ of habitat variables and landscape metrics in the $800 \mathrm{~m}$ strips around transects of the two study areas and significance of Mann-Whitney U test.

\begin{tabular}{lrrr}
\hline \multicolumn{1}{c}{ Habitat variables } & \multicolumn{1}{c}{ Sicily } & \multicolumn{1}{c}{ Crete } & P-value \\
\hline Artificial surfaces & $3.80(0.667)$ & $1.89(0.41)$ & 0.144 \\
Permanent crops & $29.33(3.783)$ & $36.54(4.51)$ & 0.179 \\
Pastures and arable lands & $44.04(4.063)$ & $2.37(1.030)$ & $<0.001$ \\
Complex cultivation patterns & $13.40(1.616)$ & $23.11(2.547)$ & 0.002 \\
Forest & $1.93(0.651)$ & $1.75(0.693)$ & 0.957 \\
Scrubland & $6.99(1.383)$ & $33.21(4.152)$ & $<0.001$ \\
H' & $1.64(0.094)$ & $1.85(0.065)$ & 0.179 \\
MSI & $1.76(0.018)$ & $3.42(0.14)$ & $<0.001$ \\
MPS & $156.9(14.22)$ & $347.71(38.51)$ & $<0.001$ \\
Distance from the sea (Km) & $15.0(1.99)$ & $7.9(1.31)$ & 0.032 \\
Altitude (m) & $235(28.0)$ & $332(40.0)$ & 0.045 \\
Slope & $18.4(0.57)$ & $9.2(0.73)$ & $<0.001$ \\
Northness & $-0.171(0.043)$ & $-0.014(0.073)$ & 0.024 \\
Ruggedness & $0.004(0.001)$ & $0.013(0.002)$ & $<0.001$ \\
Solar radiation & $1298(7.2)$ & $1502(21.3)$ & 0.124 \\
\hline H': Shannon diversity index & & & \\
MSI: mean shape index & & &
\end{tabular}

Table 3. Distance sampling models for Common buzzard and Eurasian kestrel surveys in Sicily and Crete. For each key function, we tested a number of adjustment terms, automatically selected by difference in AIC (HN: half normal, HR: hazard rate, Uni: uniform, 0: no adjustment selected, HP: hermite polynomial, Cos: cosine, SP: simple polynomial)

\begin{tabular}{lcccr}
\hline Key & $\begin{array}{c}\text { Adjustment } \\
\text { terms }\end{array}$ & Covariates & $\begin{array}{c}\text { Number of } \\
\text { parameters }\end{array}$ & $\Delta$ AIC \\
\hline HN & 0 & - & 3 & 33.10 \\
HR & 0 & - & 2 & 26.61 \\
Uni & HP & - & 1 & 113.99 \\
Uni & Cos & - & 3 & 32.16 \\
Uni & SP & - & 3 & 82.75 \\
Uni & HP & - & 5 & 156.27 \\
HN & 0 & SPECIES & 4 & 4.47 \\
HN & HP & SPECIES & 2 & 64.63 \\
HR & 0 & SPECIES & 3 & 0.00 \\
HN & 0 & ISLAND & 3 & 11.61 \\
HN & HP & ISLAND & 2 & 86.18 \\
HR & Cos & ISLAND & 4 & 40.98 \\
HR & SP & ISLAND & 3 & 63.30 \\
HR & HP & ISLAND & 4 & 63.13 \\
HN & 0 & SPECIES, ISLAND & 3 & 50.52 \\
HR & 0 & SPECIES, ISLAND & 4 & 2.62 \\
\hline
\end{tabular}

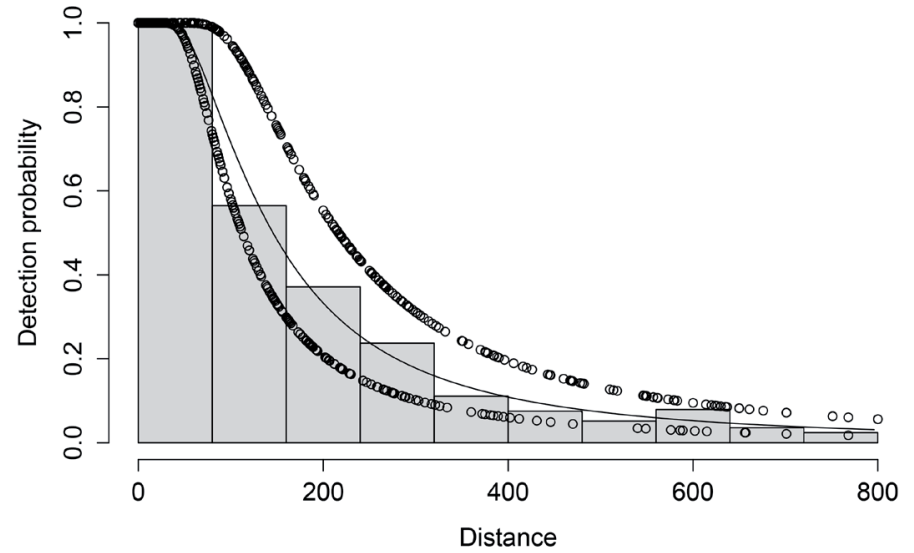

Figure 2. Histogram of the perpendicular distance from transect to detected kestrels and buzzards and detection function giving rise to the best fitting obtained using the hazard-rate key function, without series-term adjustments and species as covariate. The higher series of dots represent the detectability of the common buzzard, the lower the detectability of the Eurasian kestrel. 
Table 4. Results of the linear models of common buzzard density vs. habitat variables in Sicily and Crete ( $\beta$ : standardized regression coefficient, LCI: lower 95\% confidence interval, UCI: upper 95\% confidence interval, ‘***': $\mathrm{P}<0.001$, ‘**': $\mathrm{P}<0.01$, ‘*': $\mathrm{P}<0.05$, $\because \mathrm{P}<0.1)$.

\begin{tabular}{lrcc}
\hline \multicolumn{1}{c}{ Variable } & \multicolumn{1}{c}{$\beta(\mathrm{LCI} / \mathrm{UCI})$} & $\mathrm{P}$ & \\
\hline (Intercept) & $0.45(-0.696 / 1.596)$ & 0.732 & \\
Island (Sicily) & $-0.06(-1.219 / 1.092)$ & 0.912 & \\
Kestrel density & $1.11(0.548 / 1.666)$ & $<0.001$ & $* * *$ \\
$\mathrm{KmH}^{\prime}$ & $0.16(0.045 / 0.265)$ & 0.007 & $* *$ \\
Artificial surfaces & $0.5(0.134 / 0.871)$ & 0.009 & $* *$ \\
Orchards & $1.09(0.344 / 1.835)$ & 0.005 & $* *$ \\
Complex cultivation patterns & $0.76(0.229 / 1.295)$ & 0.006 & $* *$ \\
Forest & $0.39(0.147 / 0.638)$ & 0.002 & $* *$ \\
Scrubland & $0.83(0.234 / 1.431)$ & 0.008 & $* *$ \\
Island (Sicily)*Kestrel density & $-1.05(-1.617 /-0.487)$ & 0.001 & $* * *$ \\
Island (Sicily)*Artificial surfaces & $-0.56(-0.944 /-0.185)$ & 0.004 & $* *$ \\
Island (Sicily)*Orchards & $-1.01(-1.764 /-0.253)$ & 0.010 & $*$ \\
Island (Sicily)*Complex cultivation patterns & $-0.89(-1.435 /-0.338)$ & 0.002 & $* *$ \\
Island (Sicily)*Forest & $-0.32(-0.582 /-0.054)$ & 0.019 & $*$ \\
Island (Sicily)*Scrubland & $-0.86(-1.504 /-0.224)$ & 0.009 & $* *$ \\
\hline
\end{tabular}

Figure 3. Two-way interaction between predictor variables and density of the common buzzard in linear models in Sicily and Crete (a: kestrel density, b: artificial surfaces, c: orchards, d: complex cultivation patterns, e: scrubland, f: forest).
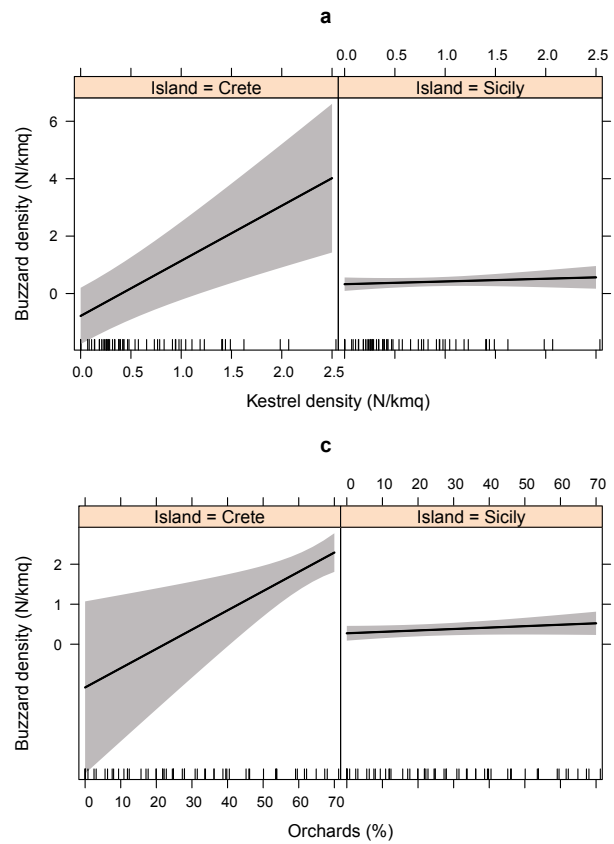

e

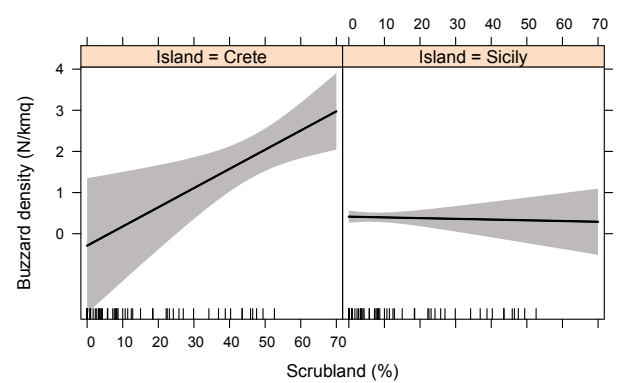

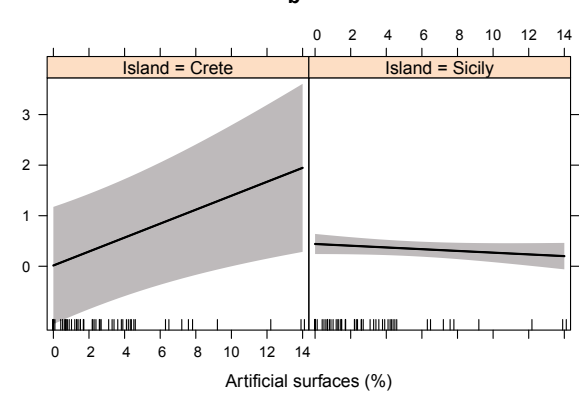

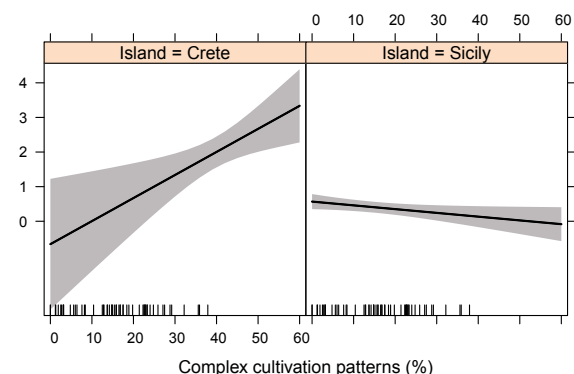

f

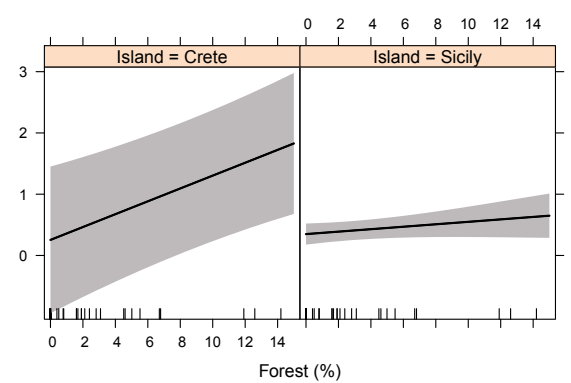


Table 5. Results of the linear models of Eurasian kestrel density vs. habitat variables in Sicily and Crete ( $\beta$ : standardized regression coefficient, LCI: lower 95\% confidence interval, UCI: upper 95\% confidence interval, '***': $\mathrm{P}<0.001$, ‘**': $\mathrm{P}<0.01$, '*’: $\mathrm{P}<0.05$, $\because \mathrm{P}<0.1)$.

\begin{tabular}{lrrc}
\hline \multicolumn{1}{c}{ Variable } & \multicolumn{1}{c}{$\beta(\mathrm{LCI} / \mathrm{UCI})$} & \multicolumn{1}{c}{$\mathrm{P}$} & \\
\hline (Intercept) & $-0.05(-0.339 / 0.248)$ & 0.756 & \\
Island (Sicily) & $1.04(0.628 / 1.461)$ & $<0.001$ & $* * *$ \\
$\mathrm{KmH}^{\prime}$ & $0.19(0.079 / 0.310)$ & 0.001 & $* *$ \\
Orchards & $0.31(0.186 / 0.439)$ & $<0.001$ & $* * *$ \\
Complex cultivation patterns & $0.21(0.029 / 0.388)$ & 0.024 & $*$ \\
Forest & $0.12(0.009 / 0.230)$ & 0.034 & $*$ \\
Scrubland & $0.24(0.063 / 0.421)$ & 0.009 & $* *$ \\
$\mathrm{H}^{\prime}$ & $-0.18(-0.359 / 0.001)$ & 0.051 & $*$ \\
Altitude & $0.03(-0.148 / 0.212)$ & 0.723 & \\
Northness & $-0.05(-0.202 / 0.104)$ & 0.522 & \\
Island (Sicily)*Altitude & $-0.24(-0.462 /-0.024)$ & 0.030 & $*$ \\
Island (Sicily)*Northness & $0.28(0.061 / 0.496)$ & 0.013 & $*$ \\
\hline
\end{tabular}

Table 6. Results of the linear models of kilometric bird diversity index vs. habitat variables in Sicily and Crete ( $\beta$ : standardized regression coefficient, LCI: lower 95\% confidence interval, UCI: upper 95\% confidence interval, ‘***': $\mathrm{P}<0.001$, ‘**': $\mathrm{P}<0.01$, ‘*’: $\mathrm{P}<$ 0.05$, ' ’ P $<0.1)$

\begin{tabular}{lrccc}
\hline \multicolumn{1}{c}{ Variable } & $\beta(\mathrm{LCI} / \mathrm{UCI})$ & \multicolumn{1}{c}{$\mathrm{P}$} & \\
\hline (Intercept) & $0.00(-0.094 / 0.094)$ & 0.222 & \\
Island (Sicily) & $0.08(-0.03 / 0.191)$ & 0.148 & \\
Buzzard density & $0.02(0.006 / 0.040)$ & 0.008 & $* *$ \\
Kestrel density & $-0.03(-0.112 / 0.049)$ & 0.432 & \\
Artificial surfaces & $-0.05(-0.110 / 0.001)$ & 0.056 & \\
Orchards & $-0.03(-0.068 / 0.003)$ & 0.070 &. \\
Complex cultivation patterns & $0.01(-0.007 / 0.034)$ & 0.202 & \\
Scrubland & $-0.03(-0.056 / 0.006)$ & 0.105 & \\
Shannon & $-0.02(-0.040 / 0.000)$ & 0.046 & $*$ \\
Slope & $-0.02(-0.040 / 0.004)$ & 0.107 & \\
North & $0.02(0.004 / 0.032)$ & 0.013 & $*$ \\
Island (Sicily)*Kestrel density & $0.05(-0.025 / 0.129)$ & 0.180 & \\
Island (Sicily)*Artificial surfaces & $0.06(0.003 / 0.117)$ & 0.040 & $*$ \\
Island (Sicily)*Orchards & $0.02(-0.013 / 0.061)$ & 0.198 & \\
Island (Sicily)*Scrubland & $0.04(-0.011 / 0.083)$ & 0.134 & \\
\hline
\end{tabular}

two islands. In terms of habitat composition, percentage of artificial surfaces around transects, orchards, complex cultivation patterns and scrubland, showed an overall positive effect on buzzard density in Crete. In Sicily, the effect of these variables was basically null (Figs 3b-3e). Model coefficients for percentage of forest around transects, showed a positive effect on buzzard density, higher in Crete (Fig. 3f). In the kestrel model (Table 5), the effect of island indicated a significantly higher density of kestrels in Sicily. As with the buzzard model, the density of the Eurasian kestrel was positively affected by the kilometric bird diversity and by the percentage of orchards, complex cultivation patterns, forest and scrubland. Unlike the buzzard model, however, no sig- nificant interaction between these predictors and the island were detected, indicating that those positive effects are likely to be equal in Sicily and Crete. Altitude and northness did not show a particular effect on the Eurasian kestrel density in Crete, whereas they showed, respectively, a negative and positive effect in Sicily (Figs 4a-4b). In the model of raptor diversity on the two islands (Table 6), density of common buzzard positively affected the response variable, whereas the kestrel did not have any effect in the model. Transects characterized by a lower habitat diversity, as shown by the negative coefficient of the Shannon diversity index, and a higher exposure to north, were associated with a higher raptor diversity. Although not confirmed by a satisfactory sta- 
a

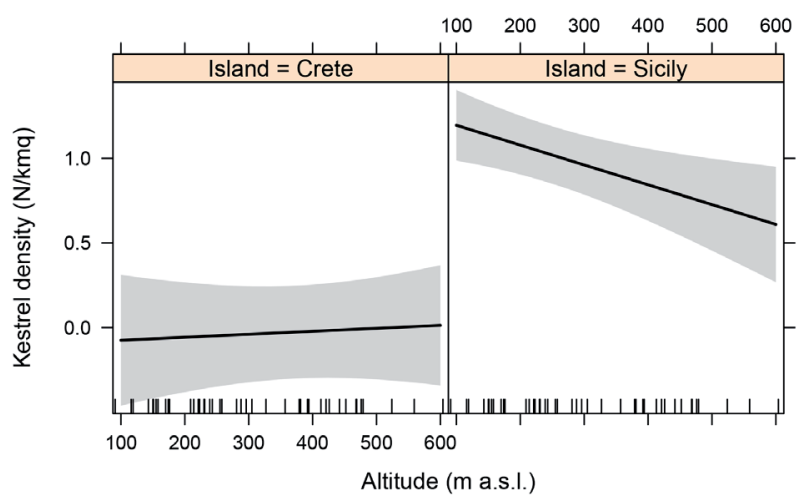

b

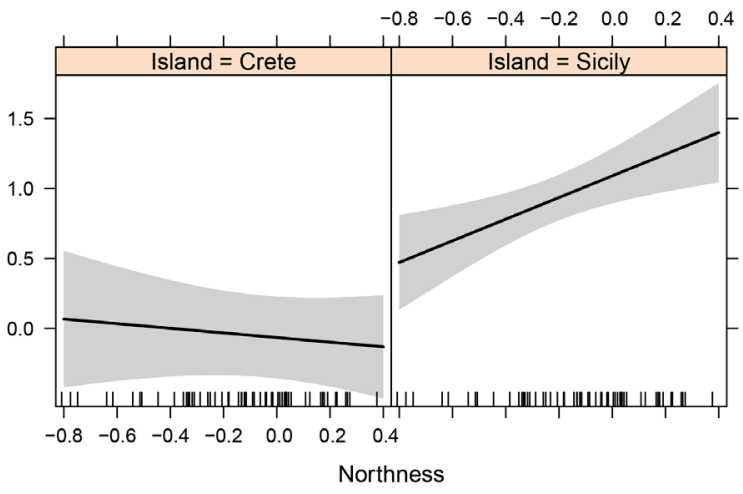

Figure 4. Two-way interaction between predictor variables and density of the Eurasian kestrel in linear models in Sicily and Crete (a: altitude, b: northness).

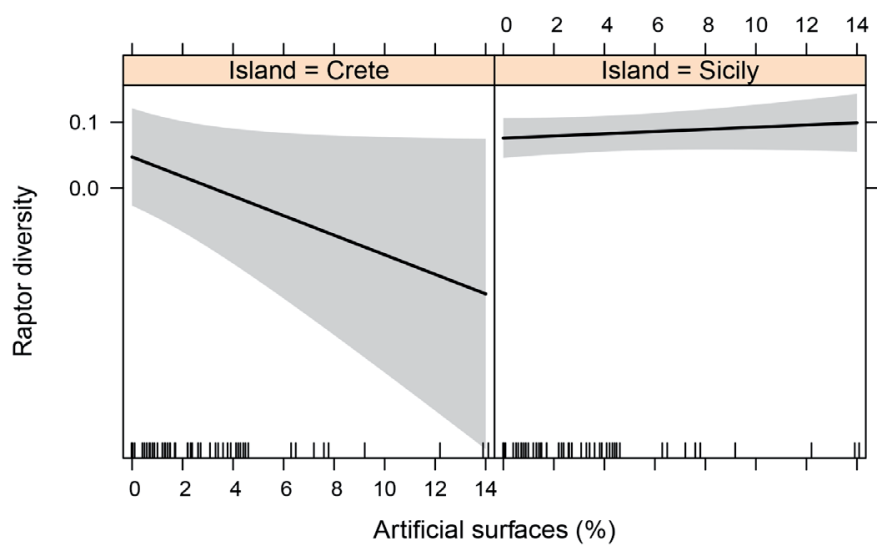

Figure 5. Two-way interaction between raptor diversity and artificial surfaces in linear models in Sicily and Crete.

tistical significance, the model seems to suggest a negative effect of artificial surfaces and orchards. Artificial surfaces in particular, were negatively associated with raptor diversity in Crete (Fig. 5).

\section{Discussion}

As shown by the Distance estimation densities, the values of the two species in the two studied islands are deeply different, with the common buzzard being most abundant in Crete and the Eurasian kestrel in Sicily. In particular, the buzzard density in Crete is more than double that of Sicily and more than three times that of the kestrel. In Sicily density of kestrel is double the density of buzzard and three times the density of kestrel in Crete. Species densities are different also for the griffon vulture, which is more widespread in Crete than in Sicily (BirdLife International 2004). This species has only recently been reintroduced into Sicily, and its population is still relatively small and localized in the northeast mountains of the island (Spinnato et al. 2013). On the other hand, the Cretan population of griffon vultures numbers approximately 400 individuals (Xirouchakis and Tsiakiris 2009). Habitat composition is rather different between the two islands with Crete showing a more rugged topography than Sicily and with fewer large patches of arable land. However, spe- cific diversity indices show similar values in the two study areas, despite differences in community composition. This is mainly due to the low numbers of vultures and large eagles in Sicily, and a scarcity of harriers in Crete (Table 1). As a general pattern, more complex raptor communities were found in flat open areas showing higher values of environment heterogeneity. This was expected since ecotonal fringes are more common in agricultural mosaic landscape than across large monocultures. Considering the variation of the kilometric bird diversity index, this was higher along northfacing slopes which are less eroded and with more vegetation in the Mediterranean landscape (Naveh 2007). Moreover, raptor communities were negatively influenced by extension of artificial surfaces. This is likely because raptor density is known to decrease in areas with extensive human settlements (Aradis and Carpaneto 2001, Baltag et al. 2013). Buzzards select more heterogeneous habitat and are less common in large homogeneous areas such as pastures and arable land (see also Wuczyński 2005). Moreover, in Crete buzzards frequent olive groves, bush areas and residual woods (see also Tzortzakaki et al. 2012). Similarly, the kestrels select areas with similar ecological features to the buzzards showing some overlap in habitat preferences. For both species, the raptor community diversity index has a positive effect on density, meaning that there is a link between community complexity and species- 
specific abundance. For other animal taxa, it has also been shown that species richness correlates with individual species densities (Evans et al. 2005, Srivastava and Lawton 1998). In particular, the 'More Individuals Hypothesis' relates the high species richness of productive sites to their suitability in supporting large populations of each species, while its power function describes the relationship between species richness (S) and individual abundance $(\mathrm{N} ; \log \mathrm{S} \propto \log \mathrm{N}$; Preston 1962, MacArthur and Wilson 1967).

\section{Interaction between the common buzzard and the Eurasian kestrel}

The common buzzard and the Eurasian kestrel are the most common raptors in both study areas as well as in most of Southern Europe and the Mediterranean region during winter (Sarà 1996, Sunyer and Viñuela 1996, Boano and Toffoli 2002). As stated before, our results showed that the density of the kestrel population was significantly lower in Crete while the opposite occurred for buzzard. Habitat heterogeneity had a positive effect on buzzard density in Crete but not in Sicily while it affected kestrel density on both islands. Considering both the large overlap in the distribution of the two species and the significant positive effect of the kestrel density to that of the buzzard in Crete, a higher inter-specific competition during winter in this island cannot be ruled out. It is known that, during the winter, buzzards feed largely on small mammals (Tóth 2014, Dare 2015, Francksen et al. 2016). This is similar to kestrels, that show a marked preference for the same prey, indicating that both species have comparable diets over this period, and thus forage in open farmland areas (Rijnsdorp et al. 1981, Village 1990, Schindler et al. 2012, Dare 2015). In this scenario, the ecological barrier represented by the Mediterranean Sea could be of paramount importance in explaining the different densities of kestrels and buzzards on the two islands. Although the buzzard is reluctant to cross large bodies of water, along the central-eastern Mediterranean flyway, substantial numbers have been recorded passing over the island of Antikythira en-route to Crete (Lucia et al. 2010, Panuccio et al. 2011, 2013). The number of buzzards in Greece during winter "is greatly augmented by immigrants" from northern and central-eastern Europe (Handrinos and Akriotis 1997), and in Crete too their number greatly increases between December and February (Tzortzakaki et al. 2012). However, once reaching this large island, buzzards are expected to stop migrating when faced with the longer water crossing (approximately $300 \mathrm{~km}$ ) towards Libya where the species is rare and most records are related to vulpinus subspecies (Panuccio et al. 2013, Isenmann et al. 2016). The same behaviour has been observed among buzzards wintering in Sicily, since the migration of the species through the central Mediterranean is virtually non-existent. (Agostini et al. 2005, Sammut et al. 2013). In this respect, we cannot exclude that substantial numbers of kestrels move along the eastern Mediterranean flyways towards their wintering quarters in Africa in response to the higher inter specific competition with the buzzard in Crete, also due to the substantial number of immigrants. Observations made in colder regions of central-northern Europe might advocate this expulsion concept, since Kestrels are quite rare there during winter, while buzzards may reach densities as high as 4.2 individuals per $\mathrm{km}^{2}$ (Schindler et al. 2012, Jankowiak et al. 2015). In addition, recent counts made at the Strait of Messina suggest that only a few dozen buzzards reach Sicily from the continent during autumn migration, with only 52 individuals observed in active migration between 15th August and 21st October 2018 (www.trektellen.org/site/totals/1594/2018, checked on 9th April 2019). This data may provide a further explanation of the higher density of kestrels on this island, however, we cannot exclude that climatic features of the two areas may influence the migratory behaviour of raptors.

In conclusion, the winter distribution of common buzzards would be more affected by its lower mobility than the Eurasian kestrels. The kestrels, having higher ability in using flapping powered flight, could reach wintering quarters in Africa leaving less favorable grounds in southern Europe, such as Crete, by undertaking the long sea crossing. Our study suggests that spatial heterogeneity of raptors in these two large Mediterranean islands is influenced by geography and further investigations are needed to develop the innovative insight to account for the motion capacity in animal distribution studies.

Acknowledgments: We are grateful to all the people who helped us during the fieldwork: A. Provenza, P. Amato, E. Giudice, P. Campo, A. Duchi and R. Ientile. We wish to thank MEDRAPTORS (www.raptormigration.org), a network of ornithologists involved in research and conservation of migrating birds of prey. A sincere thanks goes to J. Miller and F. Chadwick for their careful proofreading and English revision.

\section{References}

Agostini, N., Amato, P., A. Provenza and M. Panuccio. 2005. Do common buzzards Buteo buteo migrate across the Channel of Sicily during autumn? Avocetta 29:28.

Agostini, N., M. Panuccio and C. Pasquaretta. 2015a. Morphology, flight performance, and water crossing tendencies of AfroPalearctic raptors during migration. Curr. Zool. 1:951-958.

Agostini, N., Scuderi, A., Chiatante, G., G. Bogliani and M. Panuccio. $2015 \mathrm{~b}$. Factors affecting the visible southbound migration of raptors approaching a water surface. Ital. J. Zool. 82:186-193.

Aradis, A. and G. Carpaneto. 2001. A survey of raptors on Rhodes: an example of human impacts on raptor abundance and distribution. J. Raptor Res. 35:70-71.

Baltag, Ș.E., V. Pocora, L. Sfîcă and L. Bolboacă. 2013. Common buzzard (Buteo buteo) population during winter season in NorthEastern Romannia: the influence of density, habitat selection and weather. Ornis Fennica 90:186-192.

Beyer, H.L., E. Gurarie, L. Börger, M. Panzacchi, M. Basille, I. Herfindal, B. Van Moorter, S.R. Lele and J. Matthiopoulos. 2016. 'You shall not pass!': quantifying barrier permeability and proximity avoidance by animals. J. Anim. Ecol. 85:43-53.

Bibby, C.J., N.D. Burgess and D.A. Hill. 2000. Bird Census Techniques. Academic Press, Oxford. 
BirdLife International. 2004. Birds in Europe: population estimates, trends and conservation status. BirdLife Conservation series No. 12, Cambridge.

Boano, G. and R. Toffoli. 2002. A line transect survey of wintering raptors in the Western Po plain of northern Italy. J. Raptor Res. $36: 128-135$.

Buckland, S.T. 2001. Introduction to Distance Sampling: Estimating Abundance of Biological Populations. Oxford Univ. Press, Oxford.

Burnham K.P. and D.R. Anderson. 2002. Model Selection and Multimodel Inference: A Practical Information-Theoretic Approach. Springer, Berlin.

Büttner, G. and B. Kosztra. 2007. CLC 2006 technical guidelines. EEA Technical Report, Brussels.

Chesson, P. 2000. Mechanism of maintenance of species diversity. Ann. Rev. Ecol. Syst. 31:343-366.

Cumming, G.S., N. Gaidet and M. Ndlovu. 2012. Towards a unification of movement ecology and biogeography: conceptual framework and a case study on Afrotropical ducks. J. Biogeogr. 39:1401-1411.

Dare, P. 2015. The Life of Buzzards. Whittles Publishing, UK.

Elith J. and J.R. Leathwick. 2009. Species distribution models: ecological explanation and prediction across space and time. Annu. Rev. Ecol. Evol. Syst. 40:677-97.

Evans, K.L., J.D. Greenwood and K.J. Gaston. 2005. Dissecting the species-energy relationship. Proc. R. Soc. B. 272:2155-2163.

Francksen, R.M., M.J. Whittingham, S.C. Ludwig and D. Baines. 2016. Winter diet of Common Buzzards Buteo buteo on a Scottish grouse moor. Bird Study 63:525-532.

Guisan, A., A. Lehman, S. Ferrier, M. Austin, J.M.C. Overton, R. Aspinall and T. Hastie. 2006. Making better biogeographical predictions of species' distributions. J. Appl. Ecol. 43:386-392.

Handrinos, G. and T. Akriotis. 1997. The Birds of Greece. Helm, UK.

Isenmann, P., J. Hering, S. Brehme, M. Essghaier, K. Etayeb, E. Bourass and H. Azafzaf. 2016. Oiseaux de Libye/Birds of Libya. SEO, France.

Jankowiak, L., M. Antczak, Z. Kwiecinski, P. Szymanski, M. Tobolka and P. Tryjanowski. 2015. Diurnal raptor community wintering in an extensively used farmland. Ornis Fennica. 92:76-86.

Jung, M. 2013. LecoS - A QGIS plugin for automated landscape ecology analysis. PeerJ PrePrints: 1:e116v2.

Lucia, G., N. Agostini, M. Panuccio, U. Mellone, G. Chiatante, D. Tarini and A. Evangelidis. 2011. Raptor migration at Antikythira, in southern Greece. Brit. Birds. 104:266-270.

MacArthur, R.H. and E.O. Wilson. 1967. The Theory of Island Biogeography. Princeton Univ. Press, USA.

Malmiga, G., C. Nilsson, J. Bäckman and T. Alerstam. 2014 Interspecific comparison of the flight performance between sparrowhawks and common buzzards migrating at the Falsterbo Peninsula: A radar study. Curr. Zool. 60:670-679.

Marques, T.A., L. Thomas, S.G. Fancy and S.T. Buckland. 2007. Improving estimates of bird density using multiple-covariate distance sampling. Auk. 124:1229-1243.

Mellone, U., R. Limiñana, E. Mallìa and V. Urios. 2011. Extremely detoured migration in an inexperienced bird: interplay of transport costs and social interactions. J. Avian Biol. 42:468-472.

Meunier, F.D., C. Verheyden and P. Jouventin. 2000. Use of roadsides by diurnal raptors in agricultural landscapes. Biol. Cons. 92:291-298.

Nathan, R., W.M. Getz, E. Revilla, M. Holyoak, R. Kadmona, D. Saltz and P.E. Smouse. 2008. A movement ecology paradigm for unifying organismal movement research. Proc. Natl. Acad. Sci. 105:19052-19059.

Naveh, Z. 2007. Transdisciplinary Challenges in Landscape Ecology and Restoration Ecology - An Anthology. Springer, Berlin.

Newton, I. 1979. Population Ecology of Raptors. T. \& A.D. Poyser, UK.

Panuccio, M. 2011. Wind effects on visible raptor migration in Spring at the Strait of Messina, Southern Italy. J. Raptor Res. 45:88-92.

Panuccio, M., N. Agostini and C. Barboutis. 2013. Raptor migration in Greece: a review. Avocetta 37:1-7.

Panuccio, M., N. Agostini and G. Bogliani. 2011. Mount-Olympus: a new raptor migration bottle-neck in northern Greece. Proceedings of the XVI Italian Ornithological Congress: 31, Cervia September 2011.

Panuccio, M., N. Agostini and G. Premuda. 2012. Ecological barriers promote risk minimization and social learning in migrating Short-toed Snake Eagles. Ethol. Ecol. Evol. 24:74-80.

Panuccio, M., P. Lucia, N. Agostini, D. Ottonello and G. Bogliani. 2015. Motion capacity, geography and ecological features explain the present distribution of a migratory top predator. Ecol. Res. 30:181-190.

Preston, F.W. 1962. The canonical distribution of commonness and rarity. Ecology 43:185-215.

QGIS development team. 2014. QGIS Geographic Information System. Open Source Geospatial Foundation Project.

Rijnsdorp, A., S. Daan and C. Dijkstra. 1981. Hunting in the Kestrel, Falco tinnunculus, and the adaptive significance of daily habits. Oecologia 50:391-406.

Riley, S.J., S.D. Degloria and S. Elliot. 1999. A Terrain Ruggedness Index That Quantifies Topographic Heterogeneity. Intermt. J. Sci. 5:23-27.

Rogerson, P.A. 2001. Statistical Methods for Geography. Sage, London.

Sammut, M., N. Fenech and J.E. Pirotta. 2013. Autumn raptor migration over Malta. Brit. Birds. 106:217-223.

Sarà, M. 1996. Wintering raptors in the Central Mediterranean basin. In: Muntaner J, Mayol J (eds). Biologia y Conservación de las Rapaces Mediterraneas. Monografia n. 4, SEO, Madrid.

Schindler, S, U. Hohmann, R. Probst, H.L. Nemeschkal and G. Spitzer. 2012. Territoriality and habitat use of Common Buzzards (Buteo buteo) during late autumn in northern Germany. J. Raptor Res. 46:149-157.

Spinnato, A., F. Testagrossa and M. Geraci. 2013. Risultati del progetto di reintroduzione del Grifone Gyps fulvus nel Parco dei Nebrodi (Sicilia) e prospettive Future: anno 2012. In: Mezzavilla F, Scarton F editors. Atti Secondo Convegno Italiano Rapaci Diurni e Notturni. Treviso, 12-13 ottobre 2012. Associazione Faunisti Veneti, Quaderni Faunistici n. 3, pp. 77-82.

Srivastava, D.S. and J.H. Lawton. 1998. Why more productive sites have more species: an experimental test of theory using tree-hole communities. Amer. Nat. 152:510-529.

Sunyer, C. and J. Viñuela. 1996. Invernada de rapaces (O. Falconiformes) en España peninsular e islas Baleares. In: Muntaner, J. and Mayol, J. (eds), Biologia y Conservación de las Rapaces Mediterraneas. Monografia n. 4, SEO, Madrid.

Thomas, L., S.T. Buckland, E.A. Rexstad, J.L. Laake, S. Strindberg, S.L. Hedley, J.R.B. Bishop, T.A. Marques and K.P. Burnham. 2010. Distance software: design and analysis of distance sampling surveys for estimating population size. J. Appl. Ecol. 47:5-14. 
Tóth, L. 2014. Numerical response of the Common Buzzard Buteo buteo to the changes in abundance of small mammals. Ornis Hung. 22:48-56.

Tzortzakaki, O., S. Simaiakis and S. Xirouchakis. 2012. Abundance of common buzzards (Buteo buteo) in olive monocultures in the island of Crete. J. Biol. Res. Thessalon. 17:44-50.

Village, A. 1990. The Kestrel. T. \& A.D. Poyser, London.

Wuczyński, A. 2005. Habitat use and hunting behavior of Common Buzzards Buteo buteo wintering in south-western Poland. Acta Ornithol. 40:147-154

Xirouchakis, S. and R. Tsiakiris. 2009. Status and population trends of vultures in Greece. In: Donázar J.A. et al., (eds.), Vultures, Feeding Stations and Sanitary Legislation: A Conflict and its Consequences from the Perspective of Conservation. BiologyMunibe 29 (Suppl.). Sociedad de Ciencias Aranzadi, Donostia. pp. 154-171.

Zalles J. and K. Bildstein. 2000. Raptor watch: a global directory of raptor migration sites. BirdLife Conservation series No. 9, Cambridge.

Zar, J.H. 1999. Biostatistical Analysis. Prentice Hall. Englewood Cliffs, NJ.
Zuur, A.F., E.N. Ieno, N.J.Walker, A.A. Savaliev and G.M. Smith. 2009. Limitations of linear regression applied on ecological data. In: Mixed Effects Models and Extensions in Ecology with R.: Springer; New York. pp. 11- 33.

Zuur, A.F., E.N. Ieno and C.S. Elphick. 2010. A protocol for data exploration to avoid common statistical problems. Methods Ecol. Evol. 1:3-14.

Received January 7, 2019

Revised April 17, May 16, 2019

Accepted June 6, 2019

Open Access statement. This is an open-access article distributed under the terms of the Creative Commons Attribution-NonCommercial 4.0 International License (https://creativecommons.org/licenses/by-nc/4.0/), which permits unrestricted use, distribution, and reproduction in any medium for non-commercial purposes, provided the original author and source are credited, a link to the CC License is provided, and changes - if any - are indicated. 